Endoscopic mucosal resection (EMR) is an alternative approach for the curative treatment of early gastric cancer [1]. Endoscopic clipping devices have been developed to counter complications such as perforation [2].

We report a large gastric defect caused by EMR of an early gastric cancer, which was managed by endoscopic clipping. A 55year-old man underwent esophagogastroduodenoscopy, and an elevated lesion (type I) in the body of the stomach and a well-differentiated adenocarcinoma were found (Figure 1). Endoscopic ultrasound with miniprobes (Fujinon Co., Tokyo, Japan) demonstrated an intramucosal hypoechoic lesion. A saline injection was given and strip biopsy EMR was done with a snare needle tip $2.5 \mathrm{~cm} \times 5.5 \mathrm{~cm}$ (Wilson-Cook Medical Inc., Winston-Salem, North Carolina, USA). We then noted a large transmural defect in the gastric wall approximately $25 \mathrm{~mm}$ wide (Figure 2). Gastric air and fluids were immediately aspirated and the insufflation pump deactivated. The deflated stomach permitted approximation of the edges of the defect and six clips (HX-5LR1; Olympus Optical Co., Tokyo, Japan) were applied to quickly close the perforation (Figure 3). The patient underwent nasogastric suction, and he was treated with an antibiotic and proton-pump inhibitors. Radiographs demonstrated a pneumoperitoneum that did not require aspiration. Laboratory testing revealed leukocytosis (18000). No signs of peritoneal irritation were noted at any time. On the third day, the nasogastric tube was removed and an oral diet introduced. After 4 days the patient was asymptomatic and was discharged. Histopathological investigation revealed a $14-\mathrm{mm}$ long specimen containing an adenocarcinoma with superficial microinfiltration of the first layer of the submucosa $(\mathrm{sm} 1)$, and a minimum lesion-free margin of $2 \mathrm{~mm}$. The EMR was considered to be curative. The first follow-up endoscopy at 6 months disclosed a linear scar, and biopsies were negative for neoplasia.

\title{
Large Gastric Perforation after Endoscopic Mucosal Resection Treated by Application of Metallic Clips (Video)
}

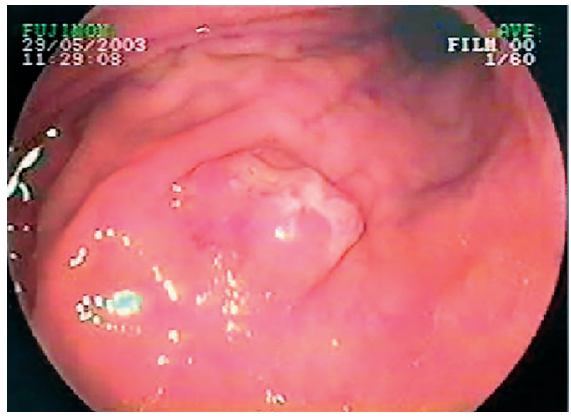

Figure 1 Endoscopic view of early gastric cancer (type I) of the body of the stomach.

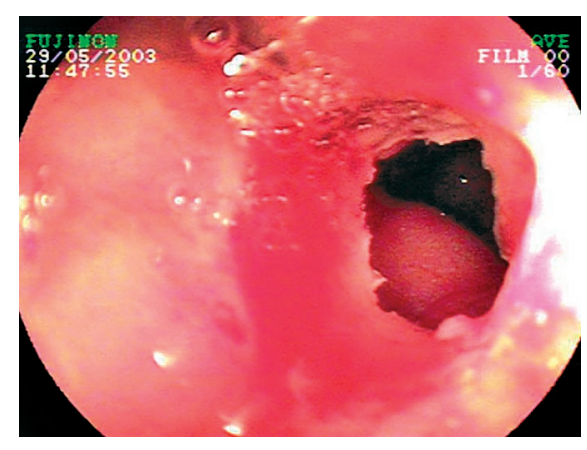

Figure 2 A large gastric perforation seen immediately after endoscopic mucosal resection. It is possible to see the peritoneal viscera.

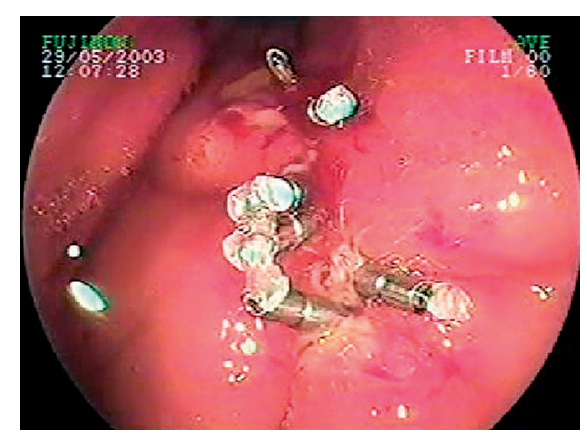

Figure 3 Six metallic clips applied to close the gastric perforation seen in Figure $\mathbf{2}$.

Perforation rates from $0.8 \%$ to $5.6 \%$ have been reported following EMR [3] and, until recently, surgical intervention was the standard approach for closure. Clipping devices have opened a new frontier in endotherapy, and small post-therapeutic iat-

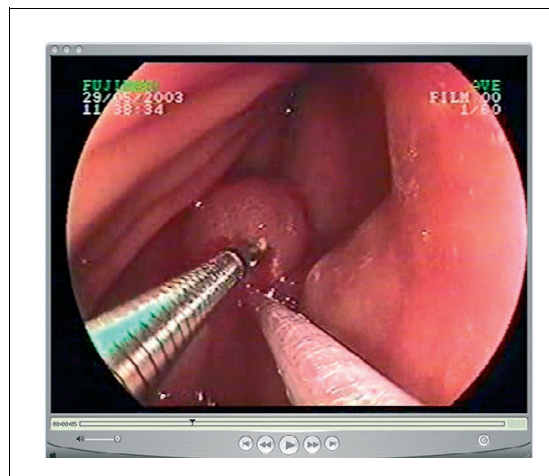

Video 1 A short video sequence augmentating this article may be found at the following link: http://www.thiemeconnect.com/DOI/DOI?10.1055/s-2004825689

A 55 year-old male underwent a strip biopsy EMR using a double-channel endoscope and the lift and cut method due to an intramucosal adenocarcinoma. A large gastric perforation was noted after the resection with free air in the abdomen. The defect was closed applying six endoscopic clips. The patient experienced an uneventful recovery with conservative management.

rogenic wall perforations have been treated successfully. Tsunada et al. reported the treatment to be successful in seven patients with gastric perforation following EMR [4]. The largest defect measured $25 \mathrm{~mm}$ and required an omental patch as well as clipping, an option described in the experimental study of Hashiba et al. [5].

We recommend that the clipping device should always be previously prepared and thus ready for use. If a perforation occurs, then to avoid peritoneal contamination the gastric contents should be immediately aspirated, the insufflation disconnected. and the repair started quickly.

\section{W. Albuquerque, V. Arantes}

Instituto Alfa de Gastroenterologia do Hospital das Clínicas da Universidade Federal de Minas Gerais, Belo Horizonte, Brazil. 
${ }^{1}$ Ono H, Kondo H, Gotoda T et al. Endoscopic mucosal resection for treatment of early gastric cancer. Gut 2001; 48: $225-229$

2 Binmoeller KF, Grimm H, Soehendra N. Endoscopic closure of a perforation using metallic clips after snare excision of gastric leiomyoma. Gastrointest Endosc 1993; 39: 172 - 174

${ }^{3}$ Ida K, Katoh T, Nakajima T et al. Outcome after using EMR according to standard guideline for endoscopic treatment of early gastric cancer. Stomach Intestine 2002; 37: 1137 - 1143
${ }^{4}$ Tsunada S, Ogata S, Ohyama T et al. Endoscopic closure of perforations caused by EMR in the stomach by application of metallic clips. Gastrointest Endosc 2003; 57: 948 - 951

${ }^{5}$ Hashiba K, Carvalho AM, Diniz GD Jr et al. Experimental endoscopic repair of gastric perforations with an omental patch and clips. Gastrointest Endosc 2001; 54: 500-504

\section{Corresponding Author}

\section{W. Albuquerque, M.D.}

Alameda Centauro 298, Ville de Montagne,

Nova Lima - MG, Brazil 34000000

Fax: $\quad+55-31-33397514$

E-mail: waltonendoscopia@uol.com.br

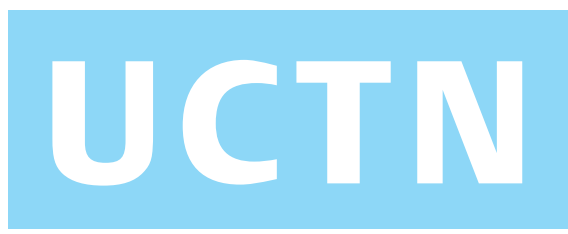

\section{Contents of Forthcoming Issue}

\section{DDW Reports}

Capsule Endoscopy

$T$ Rösch

Reflux Disease and Barrett's Esophagus $T$ Rösch

\section{Original Articles}

Histological Analysis of Endoscopic Resection Specimens from 326 Patients with Barrett's Esophagus and Early Neoplasia $M$ Vieth, C Ell, L Gossner, A May, M Stolte

Circumferential Endoscopic Mucosal Resection in Barrett's Esophagus with High Grade Intraepithelial Neoplasia or Mucosal Cancer. Preliminary Results in 21 Patients M Giovannini, E Bories, Ch Pesenti, V Moutardier, G Monges, C Danisi, B Lelong, JR Delpero
Endoscopic Resection of Submucosal Esophageal Tumors. A prospective Case Series T Wehrmann, K Martchenko, M Nakamura, A Riphaus, N Stergiou

Attempted Endoscopic En-Bloc Resection of Mucosal and Submucosal Tumors Using Insulated Tip Knives: A Pilot Series

$T$ Rösch, M Sarbia, B Schumacher, K. Deinert,

E Frimberger, T Toermer, M Stolte, $H$ Neuhaus

\section{Editorial}

Endoscopic Mucosal Resection: This is our Turf C) Lightdate

\section{Picture Gallery}

Images of Early Cancer: Esophagus Squamous Cell

T Ponchon, H Makuuchi, Y Morita, M Fukuda, T Mitani, D Shirasaka, N Aoyama, Y Amano, I Moriyama, T Oose, Y Konoshita

\section{On Writing Series (4)}

Submitting a Manuscript for Publication J Baillie 